\title{
A few challenges in mucopolysaccharidosis type I
}

a. Division of Inborn Errors of Metabolism, Hospital "Prof. Dr. Juan P. Garrahan".

b. Division of Pediatric Neurology Mucopolysaccharidosis Clinic Hospital Universitario Austral Pilar, Buenos Aires. Pediatric Ophthalmology, Universidad Católica Argentin Division of Medical Genetics, Hospital de Niños "Dr. Ricardo Gutiérrez", Autonomous City o Buenos Aires.

Hospital Privado de Córdoba. Pediatric Airway Endoscopy, Hospital "Prof. Dr. Juan P. Garrahan".

. Division of Cardiology, Hospital de Niños "Dr. Ricardo Gutiérrez".

h. Division of Audiology, Ear, Nose and Throat Department, Hospital de Niños "Dr. Ricardo Gutiérrez".

Division of Pediatric

Rheumatology, Service of

Clinical Pediatrics, Department of Pediatrics, Hospital Italiano de Buenos Aires.

Department of Hematology,

Hospital de Niños “Dr. Ricardo Gutiérrez" and Fundación Favaloro.

k. Department of Pediatric Rheumatology, Hospital de Niños "Dr. Ricardo Gutiérrez". Division of Inborn Errors of Metabolism, Hospital "Prof. Dr. Juan P. Garrahan".

11. Coordinator at the Multipurpose Day Hospital, Hospital de Niños "Dr. Ricardo Gutiérrez".

m. Department of Growth and Development, Hospital "Prof. Dr. Juan P. Garrahan".

n. Department of Metabolic Disorders, Clínica Universitaria Reina Fabiola.

ñ. Respiratory Diseases Center, Hospital de Niños "Dr. Ricardo Gutiérrez".

. Divisions of Pediatric and Adult Allergy, Hospital Italiano de Buenos Aires. Coordinator of the Food Allergy Task Force, International Life Sciences Institute (ILSI) Argentina

Growth and Development referral center in the field of Inborn Errors of Metabolism in Mendoza, Hospital Pediátrico "Dr. H. J. Notti" of Mendoza. Spinal Disease, Hospital "Prof. Dr. Juan P. Garrahan." Dr. Chamoles Laboratory.

Unit of Metabolism, Hospital Sor María Ludovica, La Plata. Department of Bone Marrow Transplant, Hospital "Prof. D Juan P. Garrahan".

Neurosurgery, Universidad de Buenos Aires (UBA), Department of Neurosurgery, Hospital "Prof. Dr. Juan P. Garrahan", former President of the International Society of the International Society (ISPN), awarded with the Latin American Federation of Neurosurgical Societies (Federación Latinoamericana de Sociedades de Neurocirugí FLANC) medal of honor in 2018.

E-mail address: Luisa B. Bay, M.D. bay.luisa@gmail.com

Funding: None.

Conflict of interest: Doctors Luisa Bay, Norberto Guelbert, Alejandro Fainboim, Norma Spécola, Guillermo Drelichman, and Marcela Pereyra have received professional fees from Sanofi for conducting teaching activities about lysosoma storage diseases.

Received: 7-21-2020 Accepted: 10-15-2020

\author{
Luisa Bay, M.D. ${ }^{a}$, Hernán Amartino, M.D. ${ }^{b}$, Alejandra Antacle, M.D. ${ }^{c}$, \\ Claudia Arberas, M.D. ${ }^{d}$, Adriana Berretta, M.D. ${ }^{e}$, Hugo Botto, M.D.f, \\ Mariana Cazalas, M.D. ${ }^{g}$, Adriana Copiz, B.S. ${ }^{h}$, Carmen De Cunto, M.D. ${ }^{i}$, \\ Guillermo Drelichman, M.D. ${ }^{j}$, Graciela Espada, M.D. ${ }^{k}$, Hernán Eiroa, M.D. ${ }^{l}$, \\ Alejandro Fainboim, M.D. ${ }^{l l}$, Virginia Fano, M.D. ${ }^{m}$, Norberto Guelber, M.D. ${ }^{n}$, \\ Alberto Maffey, M.D. ${ }^{\tilde{}}$, Claudio Parisi, M.D. ${ }^{\circ}$, Marcela Pereyra, M.D. ${ }^{p}$, \\ Rodrigo Remondino, M.D. ", Andrea Schenone, Pharmacist ${ }^{r}$, Norma Spécola, M.D. ${ }^{\text {, }}$ \\ Raquel Staciuk, M.D. ${ }^{t}$ and Graciela Zuccaro, M.D. ${ }^{u}$
}

\section{ABSTRACT}

Here we describe the current challenges of mucopolysaccharidosis type I: the need for an adequate classification, establishing its relationship to therapeutic indications; an early diagnosis, from neonatal screening, its advantages and barriers, to clinical suspicion of severe and attenuated forms; spinal and eye disease care, from diagnosis to follow-up and treatment; allergic reactions caused by enzyme replacement therapy, their diagnosis and treatment. And lastly, transition to adult care. Key words: mucopolysaccharidosis type I, neonatal screening, diagnosis, allergy, transition to adult care.

http: / / dx.doi.org/10.5546/aap.2021.eng.e193

To cite: Bay L, Amartino H, Antacle A, Arberas C, et al A few challenges in mucopolysaccharidosis type I. Arch Argent Pediatr 2021;119(3):e193-e201.

\section{INTRODUCTION}

The advances in the knowledge and follow-up of patients with mucopolysaccharidosis type I (MPS I) pose some challenges worth analyzing, including its current classification, an early diagnosis, the role of pediatricians, follow-up, and transition to adult care. ${ }^{1,2}$

\section{Classification}

MPS I patients used to be classified according to the degree of severity into three clinical forms: Hurler, Hurler-Scheie, and Scheie. Clearly differentiating each pathology is not easy. In an international attempt, a clinical score was developed unsuccessfully. ${ }^{1}$ Then two clinical forms were defined: "severe form" (SF), corresponding to what was known as Hurler syndrome, and an "attenuated form" (AF), which encompassed both Hurler-Scheie and Scheie cases. A different treatment is indicated for each clinical form; therefore, the correct diagnosis is critical. $^{2}$

The SF has been characterized by the presence of clinical signs before 12 months of age or in a patient younger than 30 months old with MPS I phenotype and developmental delay or a sibling with severe MPS I. Any other patient is considered to have the AF.

The most common signs assessed for classification included developmental delay, kyphosis, joint disease, macrocephaly, and cardiomyopathy. ${ }^{2}$ There are no biochemical markers available to differentiate between both clinical forms, and, only in some cases, a molecular test is useful. ${ }^{3}$

A comparison of data from an international registry of MPS I patients ${ }^{4}$ between Latin America (LA) (including Brazil) and the rest of the world (RoW) showed that $30 \%$ of cases in LA were SFs versus $60 \%$ in the RoW. It is worth wondering if this is because there is a different phenotype in LA or if SF patients are being classified as AFs. The classification of each patient affects their treatment indication.

An early diagnosis and treatment for both clinical forms improve prognosis. ${ }^{5,6}$ It was observed that, in infants transplanted before 9 months old, cognitive development was normal in the long term. ${ }^{7}$ In the $A F$, an early enzyme replacement therapy (ERT) improves respiratory 
and heart function, bone and joint manifestations, and quality of life. ${ }^{8}$

\section{Early diagnosis}

\section{a) Neonatal screening}

Neonatal screening allows for an early diagnosis and looks for enzyme deficiency using a blood drop on filter paper; however, results do not allow to differentiate between the SF and the AF to decide on treatment. ${ }^{9}$ Clinical signs, which may be few or absent in the newborn, may not help to establish the clinical form, and the genotype may only predict the phenotype in some cases.,10

Another hurdle of neonatal screenings is pseudodeficiency, which is frequent. In those cases, the blood drop test shows enzyme deficiency, but no disease. It is different from true deficiency by the presence or absence of glycosaminoglycans in urine: they are absent in pseudodeficiency and/or based on molecular testing. ${ }^{11}$

The initiation of ERT in a newborn with a positive screening without establishing the clinical form accurately may change the infant's phenotype, thus missing the opportunity to indicate a bone marrow transplant, and putting the infant at risk for neurodevelopmental disorders. Knowing the genotype and consulting with experienced health care providers helps to decide on treatment. ${ }^{11}$ The first study on MPS I screening was conducted in Taiwan and found a higher number of cases than when diagnosis was done clinically. ${ }^{10}$

\section{b) Clinical suspicion}

In patients with the SF, kyphosis, hernias, and recurrent rhinitis and/or otitis are striking signs leading to diagnosis. ${ }^{2}$ In patients with the $\mathrm{AF}$, joint involvement and hernias are the most remarkable signs. It has been estimated that diagnosis is delayed between 2 and 9 years since symptom onset. 12,13

A questionnaire completed by 168 patients from the USA, Europe, and Latin America (SF: $55 \%$, AF: $35 \%$, and not stated: $9 \%$ ) diagnosed between 2009 and 2013 and by 582 physicians (pediatricians and rheumatologists) showed that symptoms leading patients with the SF to seek care included respiratory distress, hernias, abdominal distension, and curvature of the spine, whereas in those with the $\mathrm{AF}$, symptoms included joint stiffness and hernias. The average age at diagnosis was 1.7 years in the SFs and 8.2 years in the AFs. In total, $25 \%$ of SF patients and $14 \%$ of AF patients had consulted
7 different specialists before being diagnosed. This evidences the need to encourage an earlier diagnosis. ${ }^{14}$ Only $20 \%$ of pediatricians and $33 \%$ of rheumatologists suspected mucopolysaccharidosis by looking at the medical record of an AF case. Due to the frequency of joint involvement in the AFs, it is important to consider it from such perspective.

\section{b.1. Joint involvement}

The AF mimics arthritis in the eyes of a rheumatologist. ${ }^{15,16} \mathrm{~A}$ differential diagnosis includes the following: ${ }^{17,18}$

- MPS I treated as rheumatic disease

- Scleroderma

- Juvenile idiopathic arthritis (JIA)

- Muscular dystrophy

- Legg-Calvé-Perthes disease

- Arthrogryposis

- Osteogenesis imperfecta

- Dermatopolymyositis

Glycosaminoglycan deposits in the joint capsule, tendons, and ligaments, and metaphyseal abnormalities with a poor bone modeling lead to stiffness, especially in the hands (claw hand) and shoulders. ${ }^{19}$ Unlike JIA, mucopolysaccharidosis does not cause inflammatory signs. Stiffness affects mainly the distal interphalangeal joints, causing claw hand and toe-walking due to the shortening of the Achilles tendon. It is not exacerbated by rest. Non-steroidal antiinflammatory drugs and corticosteroids provide no benefit, and patients do not develop acute phase reactants or autoantibodies. ${ }^{20}$

Other differential diagnoses include isolated and syndromic camptodactyly, which affects proximal interphalangeal joints, usually the fifth finger, and diabetic cheiroarthropathy, with limited metacarpophalangeal and interphalangeal mobility due to contraction. ${ }^{21}$ (Algorithm 1$)^{22}$

Twenty-five percent of carpal tunnel syndrome (CTS) cases are of idiopathic nature, secondary to median nerve compression caused by thickening of the flexor retinaculum and tendon sheaths; however, if observed in a child, MPS I should be suspected because it is present in more than $50 \%$ of patients with mucopolysaccharidosis. Diagnosis may be delayed because symptoms are not typical. ${ }^{23}$ They may bite their fingers or remove their hands when examined, are clumsy, experience motor function regression, may have reduced sweating in the affected area or suffer wakefulness during the night. Surgery prevents permanent neurologic damage. 
Out of 974 patients with MPS I, 291 had CTS. The recommendation is to screen for CTS as of 3 years old in the SF and as of 5-7 years old in the AF. ${ }^{24}$ Trigger finger (stenosing tenosynovitis) leads to clinical diagnosis. ${ }^{24}$ The pediatric Gait Arms Legs and Spine (pGALS) is an evidencebased questionnaire aimed at non-specialist physicians to assess joints following rapid maneuvers. It has a very good sensitivity to detect abnormalities. ${ }^{25-27}$

The assessment will include gait, opening and closing hands, prayer sign, shoulder rotation and abduction, hips, cervical and thoracolumbar spine, temporomandibular joint, and checking if the subject can put 3 fingers inside their mouth.
Two out of three patients with MPS I and joint involvement have restricted movement in the fingers, which may be observed at 8-10 months old. ${ }^{28}$

The presence of glycosaminoglycan deposits leads to an inflammatory and immune response. The transcription of certain osteoclastogenesisstimulating proteins causes bone destruction and increases chondrocytes apoptosis, which have a short life, leading to cell proliferation, cartilage and bone breakdown, joint destruction, and osteopenia. ${ }^{28,29}$

Given the similarities in the inflammatory process between juvenile rheumatoid arthritis and mucopolysaccharidosis, animal studies are

AlgoRithm 1. Behavior to manage joint contractures in children ${ }^{22}$

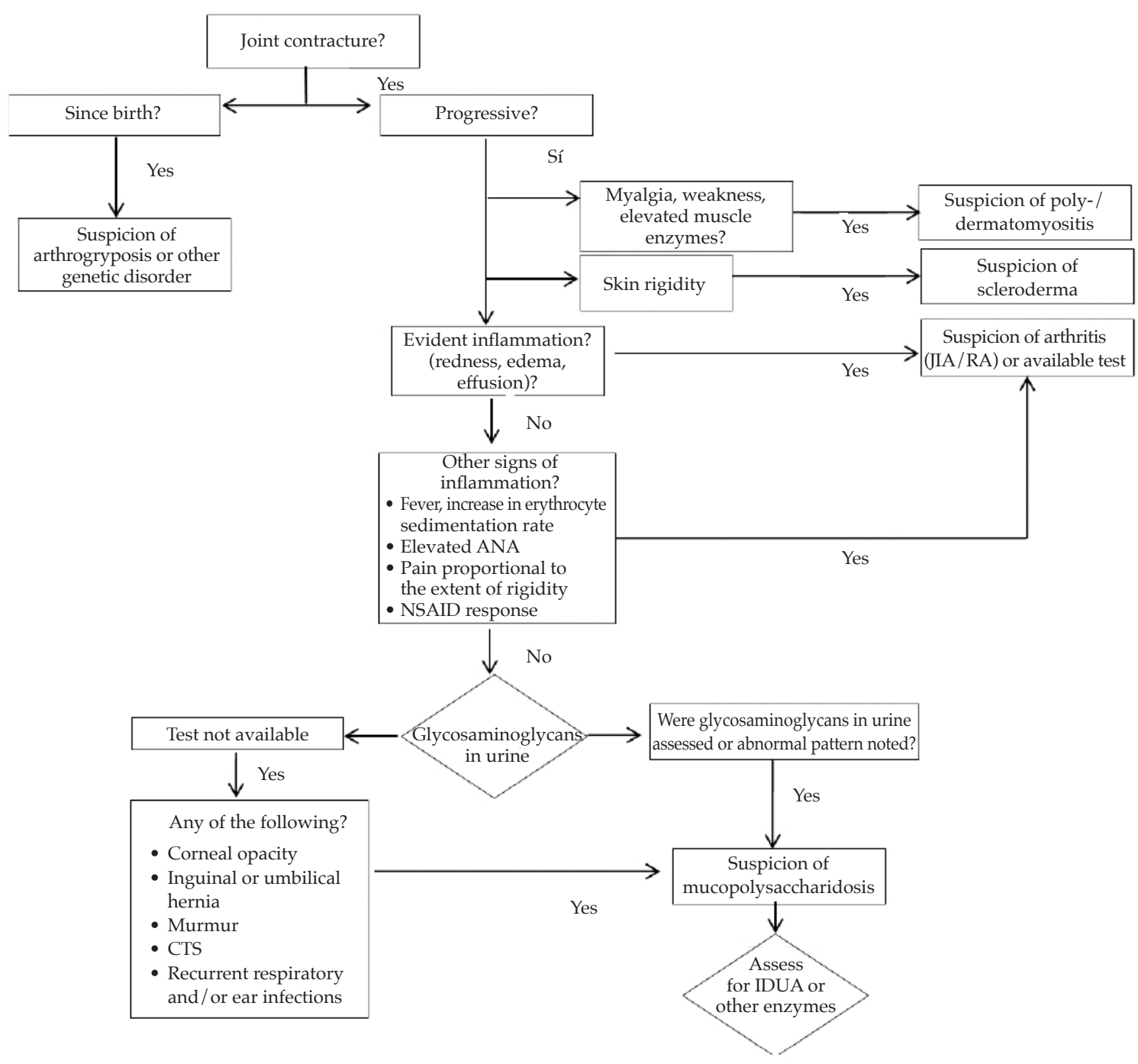

JIA: juvenile idiopathic arthritis; RA: rheumatoid arthritis; CTS: carpal tunnel syndrome;

IDUA: allelic mutations of the $\alpha$-L-iduronidase gene. 
being conducted to establish the effectiveness of biological agents, such as tumor necrosis factor (TNF) antagonists, interleukin 1 (IL-1) antagonists, and Janus kinase (JAK) signaling pathway. ${ }^{24}$

\section{b.2. Skeletal dysplasias}

Some patients seek care due to bone abnormalities, and mucopolysaccharidosis should be included in the differential diagnoses. A wide range of skeletal manifestations is known as multiple dysostosis.

Different cases of mucopolysaccharidosis may share a similar phenotype without a specific radiological sign. Short stature, altered body proportions, gait disorders, limited joint mobility, and spinal involvement serve as guidance. ${ }^{30,31}$

The radiological characteristics of multiple dysostosis occur early. They include macrocephaly, J-shaped sella, skull vault thickening, widened ribs and clavicles (paddleshaped), ovoid or hook-shaped vertebral bodies (hypoplasia of the anterior segment of the vertebral body over its profile), coxa valga, acetabular roof in a vertical position, short metacarpal bones, and proximal, pointed metaphyses of second-fifth metacarpal bones. Osteopenia and osteoporosis are observed in $31 \%$ of patients. ${ }^{31}$

A periodic assessment of height helps to detect delayed growth (changes in Z-score higher than 0.7-1). The sitting height/ height for age ratio is used to detect a short trunk. ${ }^{32}$ Macrocephaly relative to height is detected based on the head circumference/height for age ratio..$^{33}$

A study with 14 patients with the SF showed that most were born with a height and weight above the $50^{\text {th }}$ percentile, and that short stature was observed at 3-4 years old. ${ }^{34}$ Another study with 463 untreated cases from the international registry reported delayed growth as of 6 months old, although those with the SF were below the $3^{\text {rd }}$ percentile at 4 years old and those with the AF, at 9 years old. Therefore, basing MPS I detection on short stature would result in a late diagnosis. ${ }^{35}$

\section{Pediatricians and a clinical challenge}

Patients with chronic conditions, including those with MPS I, present with varying degrees of severity or progression, and usually require multiple consultations and hospitalizations. ${ }^{36}$ The pediatrician is in the first line of diagnosis and a primary care physician encouraging interdisciplinary work and maintaining a contact with the provider the family and patient feel closer to.$^{37}$ A polyvalent day hospital is optimal for outpatient follow-up in these cases, so that they can be studied for systemic involvement and receive ERT, if necessary. Pediatricians will work on improving patients' quality of life, encourage their autonomy, and ensure they receive comprehensive care, have their home adapted, and are able to go to school. The quality of life should be periodically assessed using objective instruments (PedsQL, version 4.0).

\section{Follow-up and ophthalmologic treatment: advances in corneal transplant}

This is another challenge in follow-up. There are glycosaminoglycan deposits in all eye structures. Orbital alterations, e.g., pseudoexophthalmos (shallow orbits, scaphocephaly) and hypertelorism, eyelid and extraocular muscle abnormalities (ptosis, edema or eyelid infiltrates) may occur. In $90 \%$ of cases, hyperopia due to shortening of the eyeball is observed. Thirty-six percent of patients experience ocular motility disturbances (erratic eye movements and/or nystagmus) or convergent strabismus. Intracellular vacuoles in the conjunctiva, thickened sclera, choroid with glycosaminoglycans on endothelial walls, and lens epithelial cells with cytoplasmic inclusions may be present. ${ }^{38,39}$ Corneal opacity is a predominant sign. Rods and cones are lost and retinal ganglion cells are reduced. Glaucoma may occur as a result of glycosaminoglycan deposits in the iridocorneal angle..$^{40}$ Infiltrates in the lamina cribrosa of sclera causes papilledema, which will lead to optic atrophy and scleral canal obstruction. ${ }^{41}$

A complete eye examination includes visual acuity, binocular vision exam/stereopsis, color / contrast vision (corneal edema modifies color and contrast sensitivity), visual field, biomicroscopy, tonometry and gonioscopy for glaucoma followup, corneal topography, and fundus (performed only if there is no corneal opacity). A confocal microscopy helps to decide on the corresponding surgical treatment. ${ }^{42}$

The following additional tests are performed:

- Anterior segment optical coherence tomography (to assess glycosaminoglycans in the angle) and posterior segment optical coherence tomography (to check for retinal infiltrates).

- Evoked potentials/electroretinography if the patient has vision loss. 
Corneal surgery is indicated for patients with the SF who have been transplanted or for those with the AF. ${ }^{43} \mathrm{~A}$ keratoplasty implies full study and follow-up. A penetrating keratoplasty may be performed, ideally after 12 years old; instead, an anterior lamellar keratoplasty may be done because there are practically no infiltrates in the endothelium. ${ }^{44}$ Clinical experience is limited..$^{45}$

\section{Allergic reactions and desensitization in case of immune response}

ERT may cause adverse reactions, including hypersensitivity reactions, which are part of the so-called "infusion reactions". These are clinically very similar events, regardless of the underlying pathophysiological mechanism. Their management and prognosis vary depending on the type of reaction (Tables 1 and 2).

When symptoms are mild and occur during the first treatment, without suspected sensitization or prior contact, it would be a condition mediated by complement activation or cytokine release, which would improve with a slower infusion rate and premedication before the following dose. ${ }^{46-51}$

In case of likely prior sensitization, a test for the presence of specific immunoglobulin E (IgE) should be done. If symptoms are observed in subsequent infusions (likely sensitization), an allergic reaction should be suspected and studied. If the condition is mild, a reinfusion may be attempted at a slower rate and with premedication; however, if the condition worsens, an allergist should be consulted.

If the specific IgE test is positive, desensitization may be attempted after assessing the risks and benefits for the patient together with the family and the treating team. ${ }^{52,53}$ Since this is a risky procedure, it should be performed by trained providers in a controlled setting. Although there are few case reports of laronidase treatment, all of them have been successful. ${ }^{54,55}$

TABLE 1. Description of the main infusion reactions (developed by the authors)

\begin{tabular}{|c|c|c|}
\hline Infusion reactions & Pathophysiological mechanisms & Action to be taken \\
\hline $\begin{array}{l}\text { Complement } \\
\text { activation syndrome }\end{array}$ & $\begin{array}{l}\text { Hypersensitivity reaction; } \\
\text { it results from complement activation. }{ }^{1} \\
\text { With the release of C } 3 a, C 5 a \text {, and C5b-9, which } \\
\text { may activate specific receptors in mast cells, } \\
\text { basophils, and other phagocytes, and } \\
\text { lead to the release of mediators., } \\
\text { In general, this occurs minutes after starting } \\
\text { the infusion, but it may be delayed, especially } \\
\text { if the patient received premedication } \\
\text { (redness, rash, dyspnea, chest pain). }{ }^{4}\end{array}$ & $\begin{array}{l}\text { More frequently, it occurs with the first } \\
\text { exposure; it does not require prior contact. } \\
\text { It is rarely observed during the second } \\
\text { or third treatment. } \\
\text { It is generally mild or absent during rechallenge. } \\
\text { It may cause tachyphylaxis. } \\
\text { It reacts to the infusion rate and } \\
\text { treatment with steroids and H1 antihistamines. } \\
\text { It is unpredictable. } \\
\text { Allergy tests do not work. }\end{array}$ \\
\hline $\begin{array}{l}\text { Cytokine release } \\
\text { syndrome }^{5}\end{array}$ & $\begin{array}{l}\text { Possibly due to the sustained activation } \\
\text { of several cells, such as monocytes, macrophages, } \\
\mathrm{T} \text { and B cells; it is characterized by increased } \\
\text { TNF- } \alpha \text { and IFN- } \gamma \text { levels. } \\
\text { It occurs } 1-2 \text { hours after exposure to the stimulus, } \\
\text { followed by an increase in IL-6 and } \\
\text { IL-10 levels, sometimes also in IL-2 and IL-8. } \\
\text { It causes erythema, edema, respiratory } \\
\text { distress, fever, hypotension, myalgias, etc. } \\
\text { It is life-threatening. }\end{array}$ & $\begin{array}{l}\text { Premedication, together with other measures, } \\
\text { such as a slower infusion rate, } \\
\text { has demonstrated to be effective. } \\
\text { It may cause skin, respiratory, and other } \\
\text { organ involvement, and be life-threatening. } \\
\text { There are no definite diagnostic tests. } \\
\text { The most severe cases may pose } \\
\text { a contraindication to treatment. }\end{array}$ \\
\hline Anaphylaxis ${ }^{6}$ & $\begin{array}{l}\text { It is an immediate systemic reaction that } \\
\text { occurs when a subject who has been previously } \\
\text { sensitized is re-exposed to an allergen. } \\
\text { It is caused by the immediate release of } \\
\text { vasoactive mediators in tissue mast cells and } \\
\text { peripheral basophils through an IgE-mediated } \\
\text { mechanism, which is life-threatening. }\end{array}$ & $\begin{array}{l}\text { It requires previous exposure; } \\
\text { it does not occur with the first reaction. } \\
\text { These are IgE-mediated mechanisms, } \\
\text { so a skin or serological test } \\
\text { may be done to look for the specific antibody. } \\
\text { Desensitization is a plausible treatment. }\end{array}$ \\
\hline
\end{tabular}

TNF- $\alpha$ : tumor necrosis factor alpha; IFN- $\gamma$ : interferon gamma; IL-6: interleukin 6; IL-10: interleukin 10;

IL-2: interleukin 2; IL-8: interleukin 8; IgE: immunoglobulin E. 


\section{Transition}

Transition is a planned process for the passage of adolescents or young adults from a pediatric care environment to adult care, ensuring medical care is not interrupted. Preparation will start in the pediatric setting, inquiring about autonomy milestones and responsibility guidelines in relation to health and daily life. ${ }^{56}$

TABLE 2. Definition of anaphylaxis (modified from Sampson et al. $)^{51}$

\section{Anaphylaxis is highly likely when any of the following 3 criteria are fulfilled:}

1. The patient does not know they are allergic; acute onset of disease (minutes to several hours) with involvement of the skin, mucus membranes or both (papules, pruritus, flushing, swollen lips, tongue or uvula).

And at least one of the following:

a. Respiratory compromise (dyspnea, bronchospasm, stridor, reduced peak expiratory flow, hypoxemia).

b. Hypotension associated with organ dysfunction symptoms (hypotonia, syncope, incontinence).

2. The patient knows they are allergic and two or more of the following occur rapidly after exposure to a known allergen for that patient (minutes or hours):

a. Involvement of the skin and mucous membranes.

b. Respiratory compromise.

c. Hypotension or associated symptoms, syncope or incontinence.

d. Persistent gastrointestinal symptoms (cramps, pain, vomiting).

3. The patient knows they are allergic and develops hypotension immediately after exposure to a known allergen (minutes or hours):

a. Infants and children: hypotension (depending on age) or reduction in systolic pressure of more than $30 \%$; less than 70 between 1 month and 1 year old; less than $[70+(2 \mathrm{x}$ age $)]$ between 1 and 10 years old.

b. Adults: less than $90 \mathrm{mmHg}$ or reduction of more than $30 \%$ from that person's baseline.

Algorithm 2. Management of infusion reactions to enzyme replacement therapy (modified from Doessegger $L$ et al. Clinical Development Methodology for Infusion-related Reactions with Monoclonal Antibodies. Clinical \& Translational Immunology. 2015; 4(7):e 39)

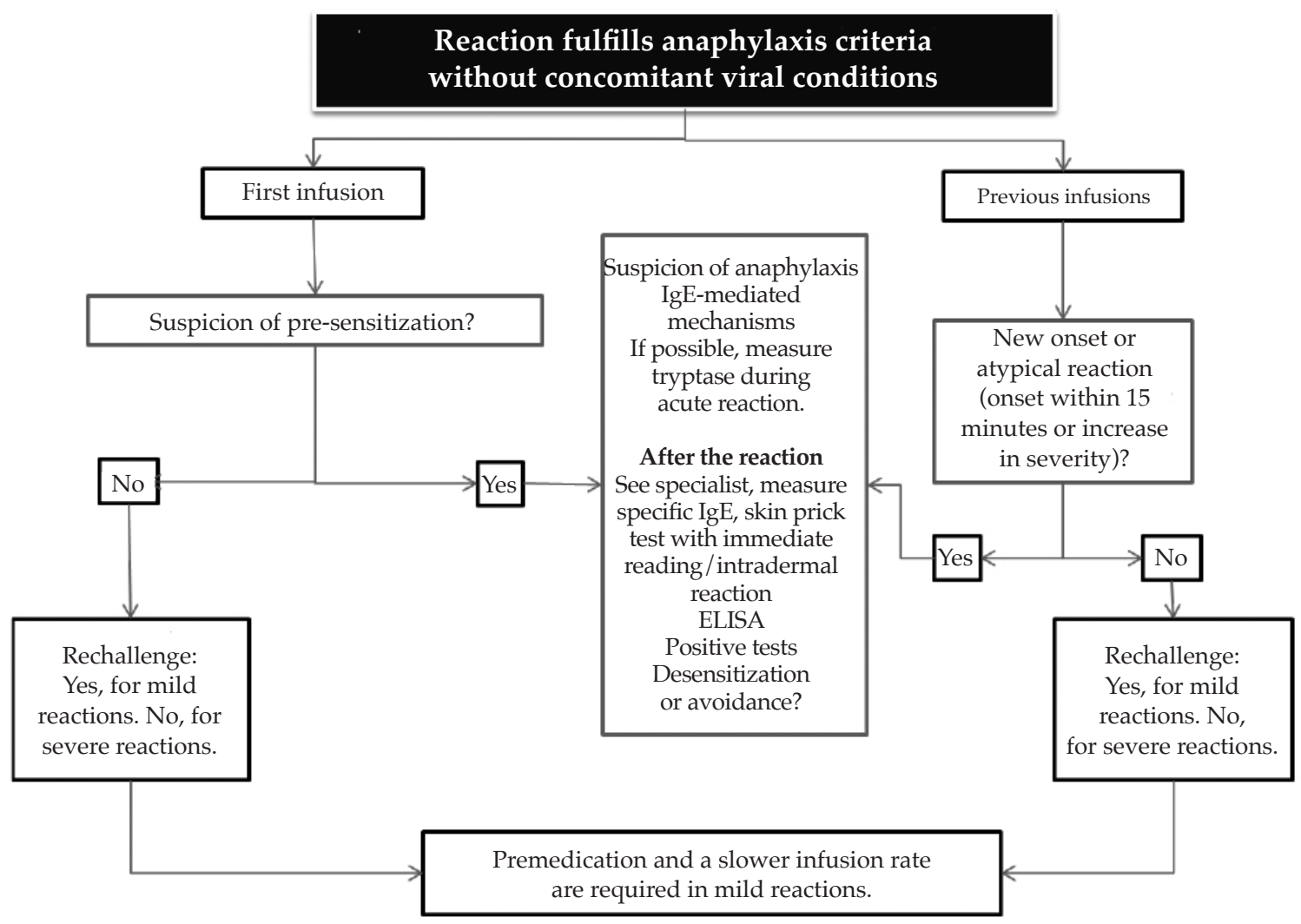

IgE: immunoglobulin E; ELISA: enzyme-linked immunosorbent assay. 
Such transition presents some barriers:

Patient barriers: dependent behavior, immaturity, disease severity, lack of trust in the new team of health care providers.

Family barriers: need for control, overprotection, emotional dependency on their pediatrician, exaggeration of disease severity, lack of trust in the new health care providers.

Pediatrician barriers: strong emotional bond with the patient and their family, feeling capable of treating young adults, lack of trust in the new team of health care providers, mixed feelings about transition.

Clinician or adult physician barriers: little knowledge about the disease, difficulty approaching the patient's psychosocial needs, uncoordinated transition, fear of more demanding consultations (long office visits, answering emails, telephone messages, etc.). ${ }^{57}$

The transition is made up of three steps:

1. Preparation: making sure, using an objective tool, that the adolescent patient is ready to manage their care in the most independent manner possible. ${ }^{58}$
2. Planning: foreseeing transition requirements and making clear each individual's responsibilities, tasks, and when they have to perform them (adolescents, parents, and health care providers).

3. Implementation: ensuring transition is as smooth and coordinated as possible.

Planning takes time, and the approach to transition should consider patients' characteristics, special care needs, and control. Each center should take patient care, not the disease, into consideration. It should warrant high-quality medical care, adequate to each stage of development, and a seamless continuation.

The coordination between the pediatric and adult care teams should be led by someone the patient and their family trust. It should include patient preparation to develop autonomy, making decisions with their family, maintaining contact, providing support, and assessing the process. ${ }^{59}$

Table 3 is an example of a transition program for patients with inborn errors of metabolism. ${ }^{60,61}$ The Sociedad Argentina de Pediatría prepared a

TABLE 3. Transition program for patients with inborn errors of metabolism ${ }^{61}$

\begin{tabular}{ll}
\hline Age/years & Plan \\
\hline 0 & $\begin{array}{l}\text { Parental education, diagnosis, treatment, warning signs. } \\
\text { Continue parental education. } \\
\text { Start patient education. }\end{array}$ \\
12 & Start education about transition. \\
13 & Assess patient knowledge about their condition. \\
14 & Encourage patient visits to the pediatrician on their own. \\
15 & Facilitate joint visits with the pediatrician and the clinician. \\
$16-18$ & Assess patient readiness. \\
& Perform a complete medical assessment and prepare reports and relevant documents. \\
& Definite transfer to the clinician. \\
\hline
\end{tabular}

TABLE 4. Transition process facilitators. SAP recommendations www.sap.org.ar/docs/profesionales/transicion_del_adolescente_con_enfermedades_cronicas.pdf

- Existence of groups of adult care sub-specialists in different centers across the country who are capable of continuing with patient follow-up.

- Most pediatric patients with chronic conditions may achieve independence and autonomy milestones (...)

- Transition clinics should be part of the hospital structure so that they do not depend on individual efforts.

- The program assessment methods should be harmonized to establish results, quality of care, and patient and family satisfaction.

- The medical history and clinical course of disease in the long-term and its impact on quality of life should be assessed (...)

- Efforts in an Ongoing Pediatric Education program for an early diagnosis and adequate follow-up should continue, and the ongoing education of clinicians and adult care sub-specialists on childhood-onset diseases should be intensified.

- Communication and coordinated work should be maintained between the pediatric and the adult care teams, the patient and their family. 
document about the transition process, including a diagnosis of the situation in Argentina, barriers and facilitators to this process (Table 4 ). ${ }^{61}$

\section{REFERENCES}

1. De Ru MH, Teunissen QG, Van der Lee JH, Beck M, et al. Capturing phenotypic heterogeneity in MPS I: results of an international consensus procedure. Orphanet J Rare Dis. 2012; 7:22

2. Muenzer J, Wraith J, Clarke L. Mucopolysaccharidosis I: Management and Treatment Guidelines. Pediatrics. 2009; 123(1):19-29.

3. Ghosh A, Mercer J, Mackinnon S, Yue W, et al. IDUA mutational profile and genotype-phenotype relationships in UK patients with Mucopolysaccharidosis Type I. Hum Mutat. 2017; 38(11):1555-68.

4. Muñoz-Rojas MV, Bay L, Sanchez L, Van Kuijck $\mathrm{M}$, et al. Clinical manifestations and treatment of mucopolysaccharidosis type I patients in Latin America as compared with the rest of the world. J Inherit Metab Dis. 2011; 34(5):1029-37.

5. Poe MD, Chagnon SL, Escolar ML. Early treatment is associated with improved cognition in Hurler syndrome. Ann Neurol. 2014; 76(5):747-53.

6. Gabrielli O, Clarke L, Ficcadenti A, Santoro L, et al. 12 year follow up of enzyme-replacement therapy in two siblings with attenuated mucopolysaccharidosis I: the important role of early treatment. BMC Med Genet. 2016; 17:19.

7. Aldenhoven M, Wynn RF, Orchard PJ, O'Meara A, et al. Long-term outcome of Hurler Syndrome patients after hematopoietic cell transplantation: an international multicenter study. Bood. 2015; 125(13):2164-72.

8. Sifuentes M, Doroshow R, Hoft R, Mason G, et al. A followup study of MPS I patients treated with laronidase enzyme replacement therapy for 6 years. Mol Genet Metab. 2007; 90(2):171-80.

9. Lin SP, Lin HY, Wang TJ, Chang CY, et al. A Pilot Newborn Screening Program for Mucopolysaccharidosis type I in Taiwan. Orphanet J Rare Dis. 2013; 8:147.

10. Kingma SDK, Langereis EJ, De Klerk CM, Zoetekouw $\mathrm{L}$, et al. An algorithm to predict phenotypic severity in mucopolysaccharidosis type $i$ in the first month of life. Orphanet J Rare Dis. 2013; 8:99.

11. Parini R, Deodato F, Di Rocco M, Lanino E, et al. Open issues in Mucopolysaccharidosis type I-Hurler. Orphanet J Rare Dis. 2017; 12(1):112.

12. Beck M, Arn P, Giuliani R, Muenzer J., et al The natural History of MPS I: global perspectives from the MPS I Registry. Gen Med. 2014; 16(10):759-65.

13. Vijay S, Wraith JE. Clinical presentation and follow up of patients with the attenuated phenotype of mucopolysaccharidosis type I. Acta Paediatr. 2005; 94(7):872-7.

14. Bruni S, Lavery C, Broomfield A. The Diagnostic Journey of Patients with Mucopolysaccharidosis I: A Real-world Survey of Patient and Physician Experiences. Mol Genet Metab Rep. 2016; 8:67-73.

15. Coppa GV. Why should rheumatologists be aware of the mucopolysaccharidosis? Rheumatology (Oxford). 2011; 50(Suppl 5):v1-3.

16. Hamilton E, Pitt P. Articular manifestations of Scheie's syndrome. Ann Rheum Dis. 1992; 51(4):542-3.

17. Aldenhoven M, Sakkers RJ, Boelens J, De Koning TJ, et al. Musculoskeletal manifestations of lysosomal storage disorders. Ann Rheum Dis. 2009; 68(11):1659-68.

18. Manger B, Mengel E, Shaefer RM. Rheumatologic Aspects of Lysosomal Storage Disease. Clin Rheumatol. 2007; 26(3):335-41.
19. Cimaz R, La Torre F. Mucopolysaccharidoses. Curr Rheumatol Rep. 2014; 16(1):389.

20. Cimaz R, Coppa G, Koné-Paut I, Link B, et al. Joint Contractures in the absence of Inflammation may indicate mucopolysaccharidosis. Pediatr RehumatolOnline J.2009;7:18.

21. Viskochil D, Muenzer J, Guffon N, Garin CH, et al. Carpal Tunnel Syndrome in Mucopolysaccharidosis I: a RegistryBased CohortStudy. DevMed Child Neurol. 2017;59(12):126975.

22. Kim HR, LeeSH. Ultrasonographic assessment of clinically diagnosed trigger fingers. Rheumatol Int. 2010;30(11):14558.

23. Foster HE, Kay LJ, Friswell M, Coady D, et al. Musculoskeletal Screening Examinations (pGLAS) for school-age children based on the adult GALS Screen. Arhritis Rheum. 2006; 55(5):709-16.

24. Foster HE, Jandial S. pGALS - paediatric Gait Arms Legs and Spine: a simple examination of the musculoskeletal system. Pediatr Rheumatol Online J. 2013; 11(1):44.

25. Chan MO, Sen ES, Hardy E, Hensman P, et al. Assessment of Musculoskeletal Abnormalities in Children with Mucopolysaccharidoses using pGALS. Pediatr Rheumatol Online I. 2014; 12:32.

26. Kiely BT, Kohler JL, Coletti HI, Poe MD, et al. Early disease progression of Hurler Syndrome. Orphanet J Rare Dis. 2017; 12(1):32.

27. Opoka-Winiarska V, Jurecka A, EmerykA, Tylki-Symanska A. Osteoimmunology in Mucopolysaccharidoses type I, II, IV and VII. Immunological regulation of the osteoarticular system in the course of metabolic inflammation. Osteoarthritis Cartilage. 2013; 21(12):1813-23.

28. Polgreen LE, Vehe RK, Rudser K, Kunin-Batson A, et al. Elevated TNF- $\alpha$ is Associated with Pain and Physical Disability in Mucopolysaccharidosis types I, II, and IV. Mol Genet Metab. 2016; 117(4):427-30.

29. ?

30. Bonafe L, Cormier-Daire V, Hall C, Lachman R, et al. Nosology and Classification of Genetic Skeletal Disorders: 2015 Revision. Am J Med Genet A. 2015; 167A(12):2869-92.

31. Różdżyńska-Świątkowska A, Jurecka A, Clieslik J, TylkiSzymańska A, et al. Growth Patterns in Children with Mucopolysaccharidosis I and II. World J Pediatr. 2015; 11(3):226-31

32. Del Pino M, Orden AB, Arenas MA, Fano V. Referencias argentinas para la evaluación de proporciones corporales desde el nacimiento hasta los 17 años. Arch Argent Pediatr. 2017; 115(3):234-40.

33. Saunders CL, Lejarraga H, Del Pino M. Assessment of head size adjusted for height: anthropometric tool for clinical use based on Argentinian data. Ann Hum Biol. 2006; 33(4):41523.

34. Tylki-Szymanska A, Rozdzynska A, Jurecka A, Marucha J, et al. Anthropometric Data of 14 Patients with Mucopolysaccharidosis I: Retrospective Analysis and Efficacy of Recombinant Human $\alpha$-L-Iduronidase (Iaronidase). Mol Genet Metab. 2010; 99(1):10-7.

35. Viskochil D, Clarke L, Bay L, Keenan H, et al. Growth patterns for untreated individuals with MPS I: Report from the international MPS I Registry. Am J Med Genet A. 2019; 179(12):2425-32.

36. World Health Organization. World report on disability. [Accessed on: October 19 ${ }^{\text {th }}, 2020$ ]. Available at: http:// www.who.int/disabilities/world_report/2011/report/ en.

37. Neufeld EF, Muenzer J. The mucopolysaccharidoses. In: Scriver CR, Beaudet AL, Sly WS, ValleD (eds.). The Metabolic and Molecular Bases of Inherited Disease. $8^{\text {th }}$ ed. New York: McGraw-Hill; 2001.Pages 3421-52. 
38. Ashworth J, Kruse FE, Bachmann B, Tormene AP, et al. Ocular manifestations in the mucopolysaccharidoses - a review. Clin Exp Ophthalmol. 2010; 38(1):12-22.

39. Bradbury JA, Martin L, Strachan IM. Acquired Brown's syndrome associated with Hurler-Scheie's syndrome. $\mathrm{Br}$ J Ophthalmol. 1989; 73(4):305-8

40. Jensen OA, Pedersen C, Schwartz M, Vestermark S, et al. Hurler/Scheie phenotype. Report of an inbred sibship with tapeto-retinal degeneration and electron-microscopie examination of the conjuctiva. Ophthalmologica. 1978; 176(4):194-204.

41. Beck M, Cole G. Disc oedema in association with Hunter's syndrome: ocular histopathological findings. $\mathrm{Br} J$ Ophthalmol. 1984; 68(8):590-4.

42. Ashworth JL, Biswas S, Wraith E, Lloyd IC. The ocular features of the mucopolysaccharidoses. Eye (Lond). 2006; 20(5):553-63.

43. Da Silva RJR, Medhi J, Pineda R. Indications for and outcomes of deep anterior lamellar keratoplasty in mucopolysaccharidoses. J Pediatr Ophthalmol Strabismus. 2013; 50(6):376-81.

44. Elbaz U, Kirwan C, Shen C, Ali A. Avoiding big bubble complications: outcomes of layer-by-layer deep anterior lamellar keratoplasty in children. Br J Ophthalmol. 2018; 102(8):1103-8.

45. Ohden KL, PitzS, AshworthJ, Maglhaes A, etal. Outcomes of keratoplasty in the mucopolysaccharidoses: an international perspective. Br J Ophtalmol. 2017; 101(7):909-12.

46. Sancho M, Breslow R, Sloane D, Castells M. Desensitization for Hypersensitivity Reactions to Medications. Chem Immunol Allergy. 2012; 97:217-33.

47. Szebeni J. Complement activation-related pseudoallergy: a new class of drug-induced acute immune toxicity. Toxicology. 2005; 216(2-3):106-21.

48. Szebeni J, Muggia F, Gabizon A, Barenholz Y. Activation of complement by therapeutic liposomes and other lipid excipient-based therapeutic products: prediction and prevention. Adv Drug Deliv Rev. 2011; 63(12):1020-30.

49. Szebeni J. Hemocompatibility testing for nanomedicines and biologicals: predictive assays for complement mediated infusion reactions. Eur J Nanomed. 2012; 4(1):33-53.

50. Bugelski PJ, Achuthanandam R, Capocasale RJ, Treacy $\mathrm{G}$, et al. Monoclonal antibody-induced cytokine-release syndrome. Expert Rev Clin Immunol. 2009; 5(5):499-521.

51. Sampson H, Muñoz-Furlong A, Campbell RL, Adkinson
NF Jr, et al. Second Symposium on the definition and management of anaphylaxis: Summary report-Second National Institute of Allergy and Infectious Disease/Food Allergy and Anaphylaxis Network symposium. J Allergy Clin Immunol. 2006; 117(2):391-7.

52. Castells MC. Desensitization for drug allergy. Curr Opin Allergy Clin Immunol. 2006; 6(6):476-81.

53. Castells MC, Tennant NM, Sloane DE, Hsu Fi, et al. Hypersensitivity Reactions to Chemotherapy: Outcomes and Safety of Rapid Desensitization in 413 cases. J Allergy Clin Immunol. 2008; 122(3):574-80.

54. Ensina LF, Sanchez Aranda C, De Lacerda AE, CameloNunes I, et al. Laronidase hypersensitivity and desensitization in type I mucopolysaccharidosis: a case report. Pediatr Allergy Immunol. 2014; 25(5):498-9.

55. Aranda C, Ensina LF, Nunes IC, Mallozi MC, etal. Diagnosis and management of infusion-related hypersensitivity reactions to enzyme replacement therapy for lysosomal diseases: the role of desensitization. J Allergy Clin Immunol Pract. 2016; 4(2):354-6.

56. White PH. Transition: a future promise for children and adolescents with special health needs and disabilities. Rheum Dis Clin N Am. 2002; 28(3):687-703.

57. De Cunto C. Transición en la atención médica, de la pediatría a la medicina del adulto. Arch Argent Pediatr. 2012; 110(4):341-7.

58. American Academy of Pediatrics; American Academy of Family Physicians; American College of Physicians; Transition Clinical Report Authoring Group, et al. Supporting the health care transition from adolescence to adulthood in the medical home. Pediatrics. 2011;128(1):182200.

59. De Cunto CL, Eymann A, Britos MÁ, González F, et al Adaptación transcultural del cuestionario de transición a la atención médica del adulto al castellano argentino Arch Arg Pediatr. 2017; 115(2):181-7.

60. Nice. Transition from children's to adult's services for young people using health or social care services. Guideline NG43. 2016. [Accessed on: April 1st 2019]. Available at: https:/ / www.nice.org.uk/guidance/ng43.

61. Pérez-López J, Ceberio-Hualde L, García Morillo JS, GrauJunyent J, et al. Proceso de transición de la asistencia pediátrica a la adulta en pacientes con errores congénitos del metabolismo. Documento de consenso. Med Clin (Barc) 2016; 147(11):506.e1-7. 